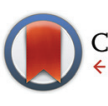

CrossMark $\leftarrow$ click for updates

Cite this: Dalton Trans., 2016, 45 11976

Received 18th April 2016, Accepted 21st June 2016

DOI: $10.1039 / \mathrm{c} 6 \mathrm{dt} 01492 \mathrm{e}$ www.rsc.org/dalton

\title{
A Ni(III) complex stabilized by silica nanoparticles as an efficient nanoheterogeneous catalyst for oxidative $\mathrm{C}-\mathrm{H}$ fluoroalkylation $\dagger$
}

\author{
Mikhail N. Khrizanforov, ${ }^{a}$ Svetlana V. Fedorenko, ${ }^{a}$ Sofia O. Strekalova, ${ }^{a}$ \\ Kirill V. Kholin, ${ }^{a}$ Asiya R. Mustafina, ${ }^{a}$ Mikhail Ye. Zhilkin, ${ }^{a}$ Vera V. Khrizanforova, ${ }^{a}$ \\ Yuri N. Osin, ${ }^{b}$ Vadim V. Salnikov, ${ }^{b}$ Tatyana V. Gryaznova ${ }^{a}$ and Yulia H. Budnikova*a
}

\begin{abstract}
We have developed $\mathrm{Ni}^{\text {III }}$-doped silica nanoparticles ([(bpy) $\left.{ }_{x} \mathrm{Ni}^{\mathrm{III}}\right]\left(\mathrm{aSiO}_{2}\right)$ as a recyclable, low-leaching, and efficient oxidative functionalization nanocatalyst for aromatic $\mathrm{C}-\mathrm{H}$ bonds. The catalyst is obtained by doping the complex $\left[(\mathrm{bpy})_{3} \mathrm{Ni}^{i \prime}\right]$ on silica nanoparticles along with its subsequent electrooxidation to $\left[(\mathrm{bpy})_{x} \mathrm{Ni}^{11 \prime}\right]$ without an additional oxidant. The coupling reaction of arenes with perfluoroheptanoic acid occurs with $100 \%$ conversion of reactants in a single step at room temperature under nanoheterogeneous conditions. The catalyst content is only $1 \%$ with respect to the substrates under electrochemical regeneration conditions. The catalyst can be easily separated from the reaction mixture and reused a minimum of five times. The results emphasize immobilization on the silica support and the electrochemical regeneration of $\mathrm{Ni}^{\text {III }}$ complexes as a facile route for developing an efficient nanocatalyst for oxidative functionalization.
\end{abstract}

\section{Introduction}

The heterogenization of homogeneous catalytic reactions allows for the facile recovery and recycling of catalysts. Transition metal complexes have gained great attention as catalysts in organic chemistry. ${ }^{1-5}$ Both immobilization of metal-based catalysts on silica supports and their silica coating are represented in the literature as routes to heterogenization. The heterogenization techniques are well documented for $\mathrm{Pd}$ in different oxidation states. ${ }^{6-9}$ It is worth noting that active species of nanocatalysts are mostly limited to only a neutral, metal(0) state, although numerous catalytic reactions require high-valent transition metals. So far, in our view, there has been only one known example of silica-supported nanocatalysts operating under oxidizing conditions. ${ }^{9} \mathrm{Pd}(\mathrm{Iv})$ species were successfully generated via oxidation of $\mathrm{Pd} @ \mathrm{SiO}_{2}$ yolk-shell nanoparticles with iodobenzene dichloride $\left(\mathrm{PhICl}_{2}\right)$ or $\mathrm{N}$-chlorosuccinimide (NCS). ${ }^{9}$ This nanocatalyst activated by $\mathrm{PhICl}_{2}$ exhibited a high level of reactivity as well as superior stability to other $\operatorname{Pd}(\mathrm{Iv})$-based catalysts in hydroalkoxylation reactions. ${ }^{9}$

\footnotetext{
${ }^{a}$ A.E.Arbuzov Institute of Organic and Physical Chemistry, Kazan Scientific Center, Russian Academy of Sciences, 8 Arbuzov Str., 420088 Kazan, Russian Federation. E-mail: yulia@iopc.ru; Fax: +7(843)275-22-53; Tel: +7(843)279-53-35

${ }^{b}$ Kazan Federal University, 18 Kremlevskaya St., Kazan 420018, Russian Federation $\dagger$ Electronic supplementary information (ESI) available: Synthesis and electrosynthesis conditions, physico-chemical characterization of catalysts and products, and other experimental details. See DOI: 10.1039/c6dt01492e
}

Interest in nickel compounds of higher oxidation states (III, IV) has now grown considerably, especially given the prospects of using them in oxidation catalysis. ${ }^{10-15}$ Although the first reports on the complexes and salts of nickel in oxidation states (III) and (Iv) appeared a relatively long time ago, ${ }^{16,17}$ there have thus far been few examples of fully characterized, isolated, and relatively stable structures demonstrated. ${ }^{18-26}$ This is due to the great difficulty in obtaining Ni(III, IV) and their stabilization, as highly oxidized nickel derivatives are very sensitive to moisture and light, and usually feature a high level of reactivity. Recently, we have demonstrated the examples of successful applications involving catalytic $\mathrm{Ni}^{\mathrm{III}}$ derivatives under electrochemical oxidation conditions ${ }^{27,28}$ as well as other electrochemically induced transformation involving nickel complexes under homogeneous conditions. ${ }^{29-33}$ Careful ligand selection is crucial in obtaining stable metal complexes in high oxidation states. Thus, fluoro-, oxo-ligands and certain macrocyclic $\mathrm{N}$-donor ligands are usually preferred for the stabilization of the highest oxidation states, both in main-group and transitionmetal chemistry. ${ }^{10-26}$ A recent report ${ }^{34}$ on the isolated $\mathrm{Ni}(\mathrm{III})$ complex [(tpy) $\left.\mathrm{Ni}^{\mathrm{III}}\left(\mathrm{C}_{4} \mathrm{~F}_{8}\right)\right]\left(\mathrm{BF}_{4}\right)$ with an identified structure exemplifies the effect of perfluoro cyclic alkyl substituents $\left(-\mathrm{C}_{4} \mathrm{~F}_{8^{-}}\right)$of ligands on stabilization of nickel in high oxidation states.

An attractive goal would be to obtain nickel derivatives in higher oxidation states, stabilized by a special environment so that they are highly effective in catalytic reactions, meanwhile easy to handle as well, and their separation from the reaction mixture, suitable for regeneration and reactivation. In this 
study, we consider one of the possible solutions to this problem, namely the stabilization of a nickel(III) complex generated electrochemically using a silicate shell in order to obtain a temporarily stable system, but nonetheless active in $\mathrm{C}-\mathrm{H}$ substitution reactions for various aromatic model systems.

Electrochemically induced nanoheterogeneous catalysis using nickel immobilized on nanoparticles has previously only been investigated for reduction conditions, where the working pair is $\mathrm{Ni}(\mathrm{II}) / \mathrm{Ni}(0){ }^{36}$ We know only of a few successful examples of solid-supported, non-metallic mediators that are easily separable and recycled in electrochemical processes. ${ }^{37,38}$ It is worth noting that the encapsulation of transition metal complexes in silica nanoparticles is not as widely applied in heterogeneous catalysis as silica surface decoration by transition metal complexes. Moreover, the accessibility of nickel complexes within silica nanoparticles for both oxidation and catalysis seems questionable. Nevertheless, a silica matrix with solvent-exposed $\mathrm{Si}-\mathrm{OH}$ and $\mathrm{Si}-\mathrm{O}^{-}$groups is a prerequisite for the extra-stabilization of Ni(III) for the purposes of both electrostatic interactions and coordination bonds.

It seems sensible to combine the advantages of two different approaches - nanoheterogeneous catalysis (easy catalyst recycling) and electrocatalysis (the generation and regeneration of the catalyst active form on the electrode surface without any additional molecular oxidant) - in order to develop a new effective catalytic technique that is both green and atom economical.

Interest in $\mathrm{C}-\mathrm{H}$ activation has grown due to the fact that the direct functionalization of hydrocarbons presents several potential advantages over traditional cross-coupling in which prefunctionalization of the substrate, for example with a halogen, is not required. Though examples of nickel-mediated $\mathrm{C}-\mathrm{H}$ activation date back to at least $1963,{ }^{35}$ the development of catalytic $\mathrm{C}-\mathrm{H}$ activation methods using nickel is a more recent development. ${ }^{10,27}$ Perfluoroalkyl groups are of special interest among fluorine-containing functional groups and new methods are necessary for incorporating them into organic substrates. $^{39-42}$

The purpose of this study is to provide stable nano-sized nickel complexes(III) with 2,2'-bipyridine ligands stabilized by a silica matrix while active during the fluoroalkylation reaction of the $\mathrm{C}-\mathrm{H}$ bonds of aromatic substrates based on the examples of some model compounds (caffeine, 2-phenylpyridine). $\mathrm{C}-\mathrm{H}$ substitution reactions will be examined as chemically variant with primarily obtained and isolated $\mathrm{Ni}^{\mathrm{III}}$ particles taken in a stoichiometric ratio as well as under electrocatalytic $\mathrm{Ni}^{\mathrm{III}}$ regeneration conditions on an anode.

\section{Results and discussion}

\section{Ni(II)-doped silica nanoparticle synthesis}

The choice of $\left[(\mathrm{bpy})_{3} \mathrm{Ni}^{\mathrm{II}}\right]$ complexes as building blocks for a nanocatalyst is based on their well-known homogeneous catalytic activity in redox transformations. ${ }^{27-33}$

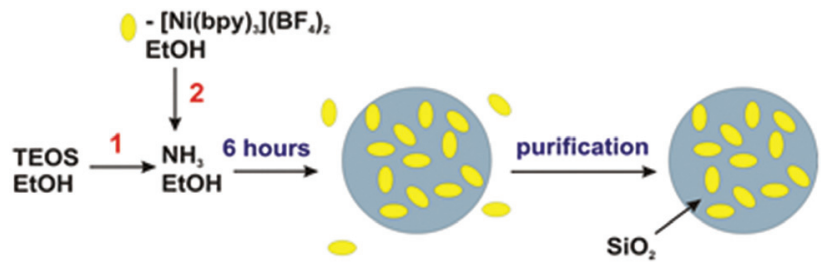

Scheme $1 \mathrm{Ni}($ ॥)-doped silica nanoparticle synthesis.

The encapsulation of tris-bipyridine complexes into silica nanoparticles is well documented in the literature by $\left[(\mathrm{bpy})_{3} \mathrm{Ru}\right]^{\mathrm{II}} \cdot{ }^{43-47}$

The previously documented Stöber procedure ${ }^{48}$ was thus optimized for the synthesis of Ni(II)-doped silica nanoparticles. Scheme 1 shows the fundamental steps in the synthesis (for further details on synthesis, see the ESI $\dagger$ ). Fig. 1 exemplifies the SEM image of $90 \pm 7 \mathrm{~nm}$ sized nanoparticles.

The Ni:Si weight ratio of 1:74 was evaluated by plasma atomic emission spectrometry of the nanoparticles with a standard deviation not greater than $10 \%$.

With the assumption that each nanoparticle weight is determined by its average size, formula (1) was then used to calculate the average weight of a nanoparticle $\left(1.1 \times 10^{-7} \mathrm{~g}\right)$. Thus, about $4 \times 10^{12} \mathrm{Ni}$ (II) ions are packed into each nanoparticle.

$$
m=4 / 3 \rho \pi r^{3},
$$

where $\rho=1.96 \mathrm{~g} \mathrm{~cm}^{3}$ for pure silica and $r$ is the radius of the nanoparticles in $\mathrm{cm}$.

The transparency of silica nanoparticles enables one to apply the electronic absorption spectra of their aqueous colloids and reveal chromophores doped in silica nanoparticles. ${ }^{49,50}$ Thus, electronic absorption spectra can reveal the presence of bipyridine ligands in silica nanoparticles. This is greatly significant, since the lability of $\left[(\mathrm{bpy}){ }_{3} \mathrm{Ni}\right]^{\mathrm{II}}$ complexes is a reason for their degradation under the conditions of alkali-catalyzed TEOS hydrolysis. Fig. 2a presents the electronic absorption spectra of $\mathrm{Ni}$ (II)-doped silica nanoparticles in acetonitrile. The spectra of bpy, $\left[(\right.$ bpy $\left.) \mathrm{Ni}^{\mathrm{II}}\right]$, and $\left[(\mathrm{bpy}){ }_{3} \mathrm{Ni}^{\mathrm{II}}\right]$ in aceto-

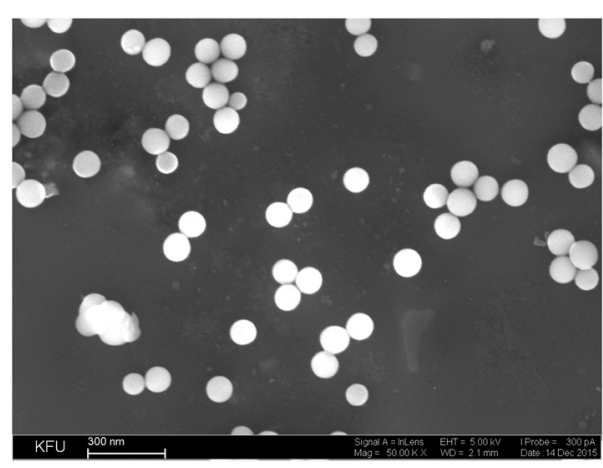

Fig. 1 SEM (scanning electron microscopy) image of silica nanoparticles doped with $\left[(\mathrm{bpy})_{3} \mathrm{Ni}\right]\left(\mathrm{BF}_{4}\right)_{2}$. 

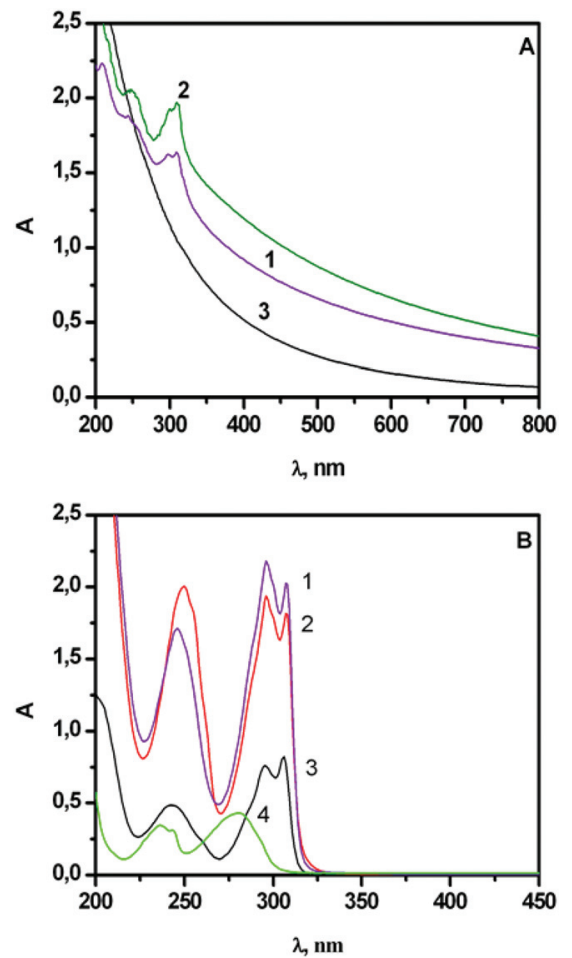

Fig. 2 The absorption spectra of the $\left[(\mathrm{bpy})_{x} \mathrm{Nil}\right] \mathrm{aSiO}_{2}$ colloids $(\mathrm{A})$ and [(bpy) $\left.{ }_{x} \mathrm{Ni}\right]$ complexes (B) in $\mathrm{CH}_{3} \mathrm{CN}$. A: [(bpy) $\left.{ }_{x} \mathrm{Ni}^{\prime \prime}\right] \mathrm{aSiO}_{2}(1),\left[(\mathrm{bpy})_{x} \mathrm{Ni}^{\prime \prime \prime}\right]$ a $\mathrm{SiO}_{2}$ (2), "empty" silica nanoparticles (3), $\mathrm{C}_{\mathrm{NiaSiO}_{2}}=2.3 \mathrm{~g} \mathrm{~L}^{-1} \cdot \mathrm{B}$ : $\left[(\text { bpy })_{3} \mathrm{Ni}^{\prime \prime}\right](1),\left[(\text { bpy })_{3} \mathrm{Ni}^{\prime l l}\right](2),\left[(\right.$ bpy $\left.) \mathrm{Ni}^{\prime \prime}\right]$ (3), bpy (4). C[(bpy $\left.)_{x} \mathrm{Ni}\right]=5 \times 10^{-5} \mathrm{M}$, $\mathrm{C}_{\text {bpy }}=10^{-5} \mathrm{M}$.

nitrile are presented in Fig. $2 \mathrm{~b}$ as well for comparison. The spectra in Fig. 2a indicate the presence of bpy molecules in the silica nanoparticles. These molecules can be either coordinated with $\mathrm{Ni}(\mathrm{II})$ ions or adsorbed by the silica matrix. Fig. $2 \mathrm{~b}$ presents different spectral patterns of "free" bpy and its complexes $\left[(\mathrm{bpy}) \mathrm{Ni}^{\mathrm{II}}\right]$ and $\left[(\mathrm{bpy})_{3} \mathrm{Ni}^{\mathrm{II}}\right]$. Comparison of the spectral patterns with the spectrum of $\mathrm{Ni}(\mathrm{II})$-doped silica nanoparticles (Fig. 2a) indicates a predominance of coordinated bpy in the synthesized nanoparticles. Nevertheless, the complex stoichiometry in silica nanoparticles cannot be accurately evaluated. Thus, the synthesized nanoparticles will continue to be designated as [(bpy $\left.)_{x} \mathrm{Ni}\right] @ \mathrm{SiO}_{2}$, where $x \leq 3$.

The electrochemical oxidation of $\left[(\mathrm{bpy})_{x} \mathrm{Ni}^{\mathrm{II}}\right] @ \mathrm{SiO}_{2}$ first calls for additional studies aimed at the evaluation of $\left[(\mathrm{bpy})_{x} \mathrm{Ni}\right]^{\mathrm{II}}$ leakage from the silica matrix into a solution. Electronic absorption spectra were applied to reveal the presence of bpy (either coordinated with $\mathrm{Ni}(\mathrm{II})$ or free) in the supernatant after continuously (1 hour) stirring $\left[(\mathrm{bpy})_{x} \mathrm{Ni}\right] @ \mathrm{SiO}_{2}$ in the acetonitrile solution with further phase separation by centrifugation. The spectra of the supernatant fit the spectral mode of "free" bpy with a small contribution of [(bpy $\left.)_{x} \mathrm{Ni}^{\mathrm{II}}\right]$ (Fig. 3). These data point to a rather small $\left[(\mathrm{bpy})_{x} \mathrm{Ni}^{\mathrm{II}}\right]$ leakage from the silica nanoparticles into acetonitrile in an hour of stirring. It is worth noting that this time duration is optimal for electrochemical or catalytic experiments, while the leakage tends to increase in the course of 2 days (Fig. 3 ).

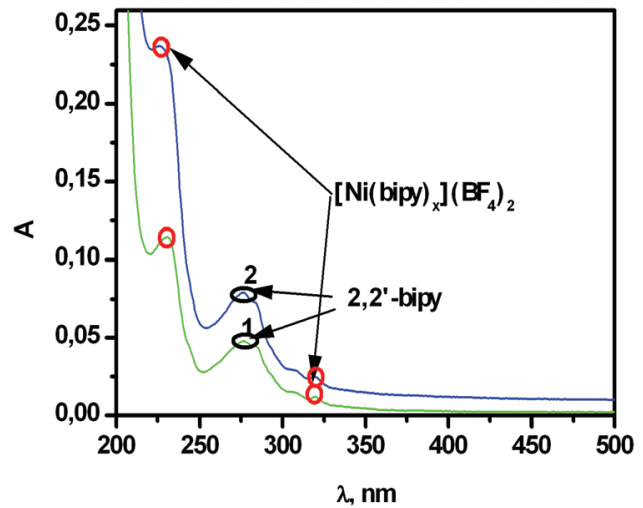

Fig. 3 The absorption spectra of the supernatants after 1 hour (1) and 2 days of continuous stirring (2) followed by the separation of [(bpy) $\left.x_{x} \mathrm{Ni}\right] @$ $\mathrm{SiO}_{2}\left(0.2 \mathrm{~g} \mathrm{~L}^{-1}\right)$ in $\mathrm{CH}_{3} \mathrm{CN}$.

The appearance of "free" bpy in the supernatant provides yet another confirmation of the partial degradation of $\left[(\mathrm{bpy}){ }_{3} \mathrm{Ni}^{\mathrm{II}}\right]$ under alkaline synthetic conditions, while no detectable amounts of $\mathrm{Ni}^{\mathrm{II}}$ ions (less than $0.001 \mathrm{mg} \mathrm{L}^{-1}$ ) are revealed in supernatants. The poor leaching of $\left[(\mathrm{bpy}){ }_{x} \mathrm{Ni}^{\mathrm{II}}\right]$ from $\left[(\text { bpy })_{x} \mathrm{Ni}^{\mathrm{II}}\right] @ \mathrm{SiO}_{2}$ into the acetonitrile (Fig. 3) confirms the above-presented assumption that the unsaturated coordinating sphere of $\left[(\mathrm{bpy})_{x} \mathrm{Ni}^{\mathrm{II}}\right]$ can be a reason for its coordination via $\mathrm{Si}-\mathrm{O}^{-}$groups of the silica matrix. Thus, the loading of silica nanoparticles by $\left[(\text { bpy })_{3} \mathrm{Ni}^{\mathrm{II}}\right]$ differs from $\left[(\text { bpy })_{3} \mathrm{Ru}^{\mathrm{II}}\right]$. In the latter case, the kinetic inertness of $\left[(\mathrm{bpy})_{3} \mathrm{Ru}^{\mathrm{II}}\right]$ prevents its degradation under synthetic conditions. Thus, the binding of $\left[(\mathrm{bpy})_{3} \mathrm{Ru}^{\mathrm{II}}\right]$ in the silica matrix is contributed by electrostatic and van der Waals interactions only, while $\left[(\mathrm{bpy})_{x} \mathrm{Ni}^{\mathrm{II}}\right]$ can be bound with silica via coordination bonds. These coordination bonds should have an effect on the redox properties of $\left[(\mathrm{bpy})_{x} \mathrm{Ni}^{\mathrm{II}}\right] @ \mathrm{SiO}_{2}$.

\section{Cyclic voltammetry}

The redox properties of the nickel(II) complex in the silica nanoparticles were examined using cyclic voltammetry. For this purpose, both the suspension of nanoparticles dispersed ultrasonically in acetonitrile was used as well as a paste electrode based on the phosphonium salt previously proven for analyzing redox properties of insoluble and low-soluble complexes with a wide range of potential. ${ }^{51,52}$ The obtained electrochemical characteristics were compared with the initial $\left[(\text { bpy })_{3} \mathrm{Ni}\right]\left(\mathrm{BF}_{4}\right)_{2}$ complex data (Fig. 4, Table 1).

The ratio of cathodic to anodic $i_{\mathrm{c}} / i_{\mathrm{a}}$ currents is approximately equal to 1 for both [(bpy $\left.)_{3} \mathrm{Ni}^{\mathrm{II}}\right]$ in the solution and doped into silica nanoparticles in the paste electrode (Fig. 4). This fact indicates the $\mathrm{Ni}^{\mathrm{III}}$ stability in cyclic voltammetry for both solutions and colloids in the time scale of voltammetry.

\section{Electrosynthesis and ESR of $\left[(\mathrm{bpy})_{x} \mathrm{Ni}^{\mathrm{III}}\right] @ \mathrm{SiO}_{2}$}

A nickel(III) complex doped into silica nanoparticles [(bpy $)_{x}$ $\left.\mathrm{Ni}^{\mathrm{II}}\right] @ \mathrm{SiO}_{2}$ was obtained using preparative electrolysis by oxidation of $\left[(\mathrm{bpy})_{x} \mathrm{Ni}^{\mathrm{II}}\right] @ \mathrm{SiO}_{2}$ on an anode (eqn (1)). Anodic oxi- 


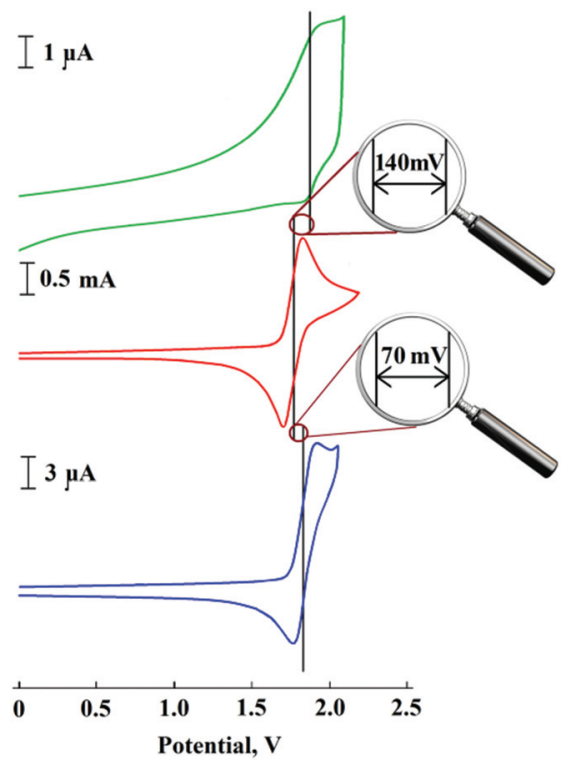

Fig. $4 \mathrm{CVs}$ of oxidation: [(bpy) $\left.)_{x} \mathrm{Ni}^{\prime \prime}\right] \mathrm{aSiO}_{2}$ suspension in $\mathrm{CH}_{3} \mathrm{CN}$ (green) [0.1 $\mathrm{g} \mathrm{L}^{-}, \mathrm{GC}$ electrode]; [(bpy $\left.)_{3} \mathrm{Ni}\right]\left(\mathrm{BF}_{4}\right)_{2}, 0.1 \mathrm{mg}$, in the modified carbon paste electrode (CPE) (red); [(bpy) $\mathrm{Ni}] \mathrm{aSiO}_{2}, 0.1 \mathrm{mg}$, in CPE (blue). Potential ref. $\mathrm{Ag} / \mathrm{AgCl}, 100 \mathrm{mV} \mathrm{s}^{-1}$.

Table 1 Electrochemical data for the nickel complex oxidation: peak potentials for the $\mathrm{Ni}^{i \prime} / \mathrm{Ni}^{\prime \prime \prime}$ couple. Conditions: $25^{\circ} \mathrm{C}, \mathrm{Ag} / \mathrm{AgCl}$ ref. electrode, $100 \mathrm{mV} \mathrm{s}^{-1}$. CPE - modified carbon paste electrode

\begin{tabular}{lllll}
\hline & & \multicolumn{3}{l}{ Potentials, $\mathrm{l}$} \\
\cline { 3 - 5 } Complex & Conditions & $E_{\mathrm{p}}{ }^{\mathrm{a}} / E_{\mathrm{p}}{ }^{\mathrm{c}}$ & $\Delta E_{\mathrm{p}}{ }^{\mathrm{a}-\mathrm{c}}$ & $E_{1 / 2}$ \\
\hline$\left[(\mathrm{bpy})_{x} \mathrm{Ni}\right] @ \mathrm{SiO}_{2}$ & $\mathrm{CPE}$ & $1.92 / 1.77$ & 0.15 & 1.84 \\
{$\left[(\mathrm{bpy})_{3} \mathrm{Ni}\right]\left(\mathrm{BF}_{4}\right)_{2}$} & $\mathrm{CH}_{3} \mathrm{CN}$ suspension & $1.94 / 1.88$ & 0.06 & 1.91 \\
& $\mathrm{CH}_{3} \mathrm{CN}$ solution & $1.83 / 1.70$ & 0.13 & 1.77 \\
& & $1.85 / 1.78$ & 0.07 & 1.82
\end{tabular}

dation is effective for $\left[(\mathrm{bpy})_{x} \mathrm{Ni}^{\mathrm{II}}\right] @ \mathrm{SiO}_{2}$ coated on the anode surface through their mixing with phosphonium salt dodecyl (tri-tert-butyl) phosphonium tetrafluoroborate. Moreover, the oxidation of $\left[(\mathrm{bpy})_{x} \mathrm{Ni}^{\mathrm{II}}\right] @ \mathrm{SiO}_{2}$ is also efficient in the acetonitrile solution of the background salt $\mathrm{Bu}_{4} \mathrm{NBF}_{4}$, wherein the nanoparticles are suspended. Successful implementation of the anodic oxidation in the colloidal dispersion of nanoparticles is atypical for heterogeneous systems. The explanation for this fact may be the good adsorption of nanoparticles on the anode surface. The driving force of the adsorption is probably an electrostatic attraction of nanoparticles doped with cations (as with ions and nickel complexes), on the anode.

$$
\left[(\text { bpy })_{x} \mathrm{Ni}^{\mathrm{III}}\right] @ \mathrm{SiO}_{2}-1 \mathrm{e} \rightleftharpoons\left[(\text { bpy })_{x} \mathrm{Ni}^{\mathrm{III}}\right] @ \mathrm{SiO}_{2}
$$

The size of the isolated $\left[(\mathrm{bpy})_{x} \mathrm{Ni}^{\mathrm{III}}\right] @ \mathrm{SiO}_{2}$ particles is almost identical to the original $\left[(\mathrm{bpy})_{x_{x}} \mathrm{Ni}^{\mathrm{II}}\right] @ \mathrm{SiO}_{2}$ (Fig. 5).

Fig. 2b illustrates the spectra of $\left[(\mathrm{bpy})_{3} \mathrm{Ni}^{\mathrm{II}}\right]$ and electrochemically generated $\left[(\text { bpy })_{3} \mathrm{Ni}^{\mathrm{III}}\right]$ in acetonitrile solutions. The

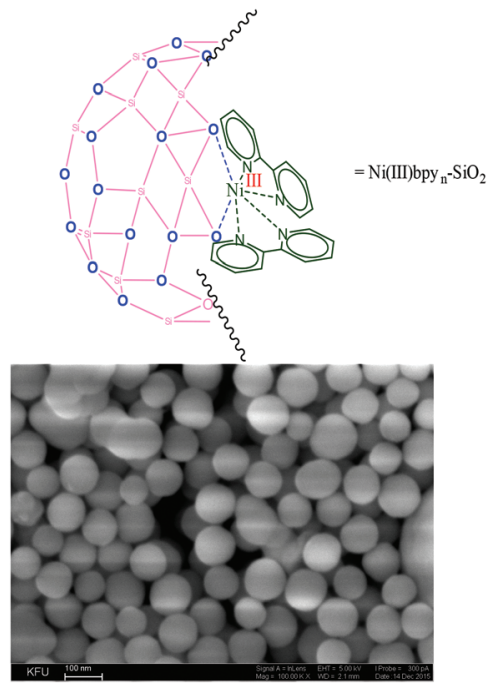

Fig. 5 Scheme of an oxidized $\left[(\mathrm{bpy})_{x} \mathrm{Ni}^{\mathrm{ill}}\right] \mathrm{CSiO}_{2}$ complex electrochemically obtained and an SEM image of the nanoparticles.

difference in their spectral modes (spectra 1, 2 in Fig. 2b) is not great, but still detectable. Nevertheless, the difference between $\left[(\mathrm{bpy})_{x} \mathrm{Ni}\right] @ \mathrm{SiO}_{2}$ before and after electrochemical oxidation (spectra 1, 2 in Fig. 2a) is not as obvious as in the solution (Fig. 2b) due to the light scattering phenomenon in the colloids. Thus, ESR spectroscopy must be applied in order to confirm the electrochemical generation of $\left[(\mathrm{bpy})_{x} \mathrm{Ni}^{\mathrm{III}}\right]$ in the silica nanoparticles.

The presence of a $\mathrm{Ni}^{\mathrm{III}}$ center in an electrogenerated [(bpy $)_{x^{-}}$ $\left.\mathrm{Ni}^{\mathrm{III}}\right] \mathrm{SiO}_{2}$ was confirmed by ESR spectroscopy. The ESR spectra were compared with those of $\left[(\mathrm{bpy})_{3} \mathrm{Ni}^{\mathrm{III}}\right]$ in the $\mathrm{CH}_{3} \mathrm{CN}$ solution, as well as their stability over time was analyzed. The electrochemically generated [(bpy $\left.{ }_{3} \mathrm{Ni}^{\mathrm{III}}\right]$ complex in the acetonitrile solution at ambient temperature yields an isotropic ESR spectrum, the intensity of which exhibits a two-fold decrease within 4.5 hours (Fig. 6). This decrease results from the instability of $\left[(\mathrm{bpy})_{3} \mathrm{Ni}^{\mathrm{III}}\right]$ in acetonitrile solutions, which is the reason for $\mathrm{Ni}^{\mathrm{III}}$ to $\mathrm{Ni}^{\mathrm{II}}$ transfer. This instability is the reason for unsuccessful doping of the electrochemically generated $\left[(\mathrm{bpy}){ }_{3} \mathrm{Ni}^{\mathrm{III}}\right]$ in acetonitrile solution into the silica nanoparticles according to the applied procedure.

The powder of the electrochemically generated nanoparticles $\left[(\mathrm{bpy})_{x} \mathrm{Ni}^{\mathrm{II}}\right] @ \mathrm{SiO}_{2}$ separated from either the background solutions or phosphonium salt was studied by ESR spectroscopy. The single band with $g=2.18$ revealed in the ESR spectra of the nanoparticles (Fig. 7) indicates paramagnetic Ni(III) complexes within silica nanoparticles. Although the main band is reproduced in the repeated measurements, the ESR spectral pattern is somewhat affected by the ampoule rotation (Fig.1S $\dagger$ ). The observed anisotropy can be explained by the nanoparticle aggregation in the concentrating and drying processes. Moreover, the presence of the preferred directions for nanoparticle aggregates in the ampoule demonstrates asymmetrically formed aggregates, such as "chain" aggregation. It should be noted that the experimentally 

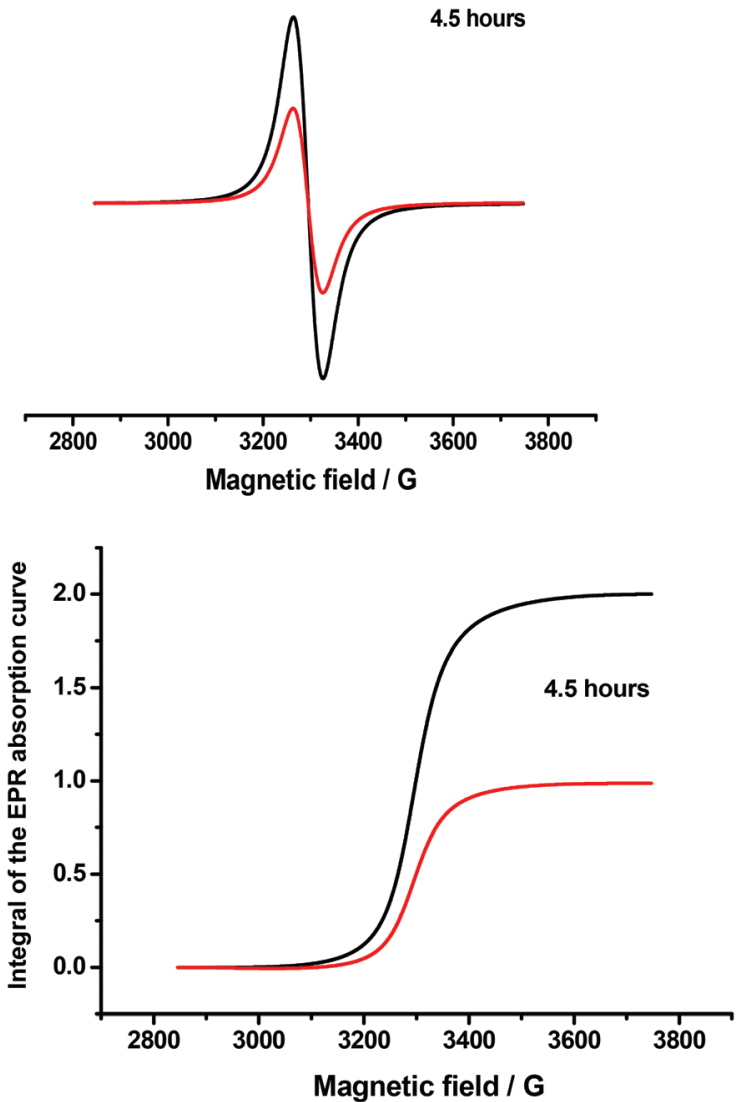

Fig. 6 The ESR spectra of the $\left[(\mathrm{bpy})_{3} \mathrm{Ni}^{\prime \prime \prime}\right]\left(\mathrm{BF}_{4}\right)_{3}$ complex in $\mathrm{CH}_{3} \mathrm{CN}$ and its parameters: $g=2.097 ; \mathrm{dH}=62 \mathrm{G}$ (left) along with the reducing signal intensity over time (right).
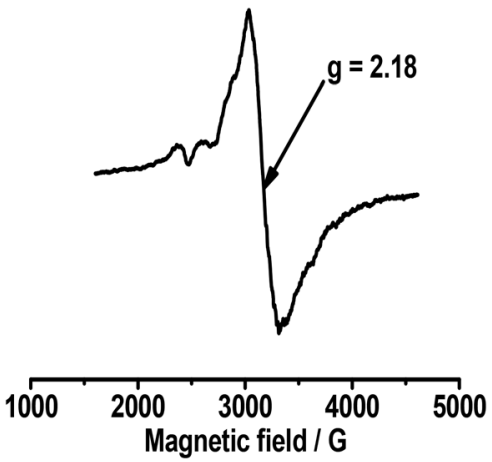

Fig. 7 ESR $\left[(\text { bpy })_{x} \mathrm{Ni}^{i \prime \prime}\right] \mathrm{aSiO}_{2}$ (powder) spectrum.

observed ESR signal does not correspond to the $\left[(\mathrm{bpy})_{3} \mathrm{Ni}^{\mathrm{III}}\right]$ complex signal in a frozen solution with $g=2.10$, which is followed in both of our experiments, as well as stated in the literature. ${ }^{53}$ This observation confirms the hypothesis that the first coordination sphere of the nickel complex inside the nanoparticles has changed. At the same time, there are many examples of complexes with low-spin $\mathrm{Ni}^{\mathrm{III}} 3 \mathrm{~d}^{7}(S=1 / 2)$ (including those doped in silica) with $g$-factors, close to the one we observed, $g=2.18 .^{54-56}$ The intensity of the ESR $\left[(\mathrm{bpy})_{x} \mathrm{Ni}{ }^{\mathrm{III}}\right]$ @
$\mathrm{SiO}_{2}$ spectrum does not change to any great extent within a few months (error $\pm 10 \%$ ), indicating the stability of the obtained $\mathrm{Ni}^{\mathrm{iII}}$ complexes inside the nanoparticles. Thus, for the first time, we have succeeded in obtaining a $\mathrm{Ni}^{\mathrm{III}}$ complex that remains stable for a long time due to stabilization of the silica matrix. Moreover, it was kept in a closed flask in the dark, but not under argon, and all operations were performed without the use of special protective measures, without a Schlenk system.

\section{Oxidative C-H fluoroalkylation of arenes}

The isolated $\left[(\mathrm{bpy})_{x} \mathrm{Ni}^{\mathrm{iI}}\right] @ \mathrm{SiO}_{2}$ nanoparticles were used as an oxidant in the chemical coupling reaction of arenes (2-phenylpyridine and caffeine) and perfluoroheptanoic acid (eqn (2), Scheme 2). Mixing the reactants and oxidant in an equal amount, for example [caffeine- $\mathrm{H}+\mathrm{HC}(\mathrm{O}) \mathrm{OC}_{6} \mathrm{~F}_{13}+$ nanoNi(III)] $=[1: 1: 2($ on Ni) $]$ in acetonitrile, led to the rapid formation of a C-H perfluoroalkylation product with $100 \%$ yield according to the ${ }^{19} \mathrm{~F}$ NMR data.

It has been discovered that an effective coupling of the selected arenes and perfluoroheptanoic acid can be carried out under electrochemically generated conditions and regenerate an active catalyst from $\left[(\mathrm{bpy})_{x} \mathrm{Ni}^{\mathrm{III}}\right] @ \mathrm{SiO}_{2}$ when the nickel content is small in relation to the reagents, $1 \mathrm{~mol} \%$ (eqn (3), Scheme 2). This reaction has also been successful. As a result of the initial substrate's $100 \%$ conversion, a perfluoroalkylation product is formed with an isolated yield of $75-85 \%$. Interestingly, $\mathrm{CO}_{2}$ gas evolution was observed at room temperature. The yields of the substituted products, namely phenylpyridine, are higher than the previously described methods for obtaining them under homogeneous conditions ${ }^{27}$ and for caffeine they are comparable with better results. ${ }^{42}$

It is worth noting the insignificant leaching of [(bpy $\left.)_{x} \mathrm{Ni}^{\mathrm{III}}\right]$ from $\left[(\mathrm{bpy})_{x} \mathrm{Ni}\right] @ \mathrm{SiO}_{2}$ during the reaction. The low leaching enabled [(bpy) $\left.)_{x} \mathrm{Ni}\right] @ \mathrm{SiO}_{2}$ to be recycled and reused 5 times for $\mathrm{C}\left(\mathrm{sp}^{2}\right)-\mathrm{H}$ bond functionalization (Table 2). The conversion of caffeine in the fifth synthesis with the same portion of the nanocatalyst has decreased by $6-8 \%$ according to the NMR spectra and the preparative yield for fluoroalkylated caffeine decreased by about the same amount. Moreover, the reaction cannot be repeated when the catalyst is extracted from the syn-

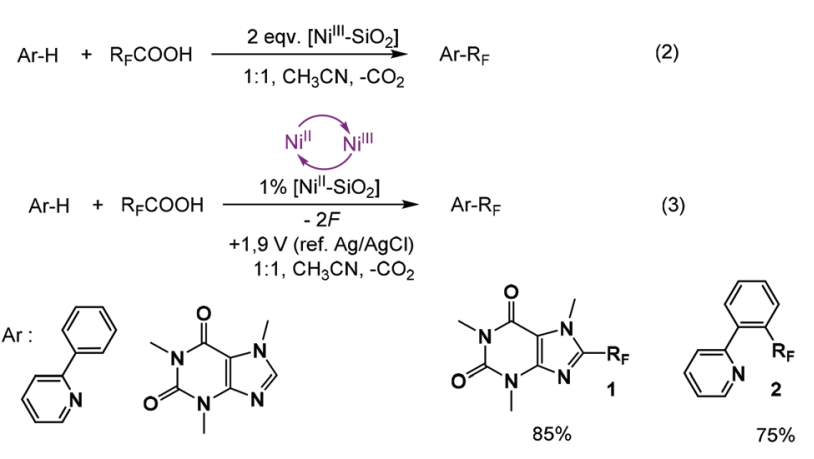

Scheme 2 Perfluoroalkylation of arenes with the $\left[(\mathrm{bpy})_{x} \mathrm{Ni}^{i l l}\right]-\mathrm{SiO}_{2}$ catalyst. 
Table 2 Conditions and yields of arene perfluoroalkylation using a recycled [(bpy) $\left.\mathrm{Ni}\left(\mathrm{SiO}_{2}\right)_{170}\right]$ catalyst (1\%)

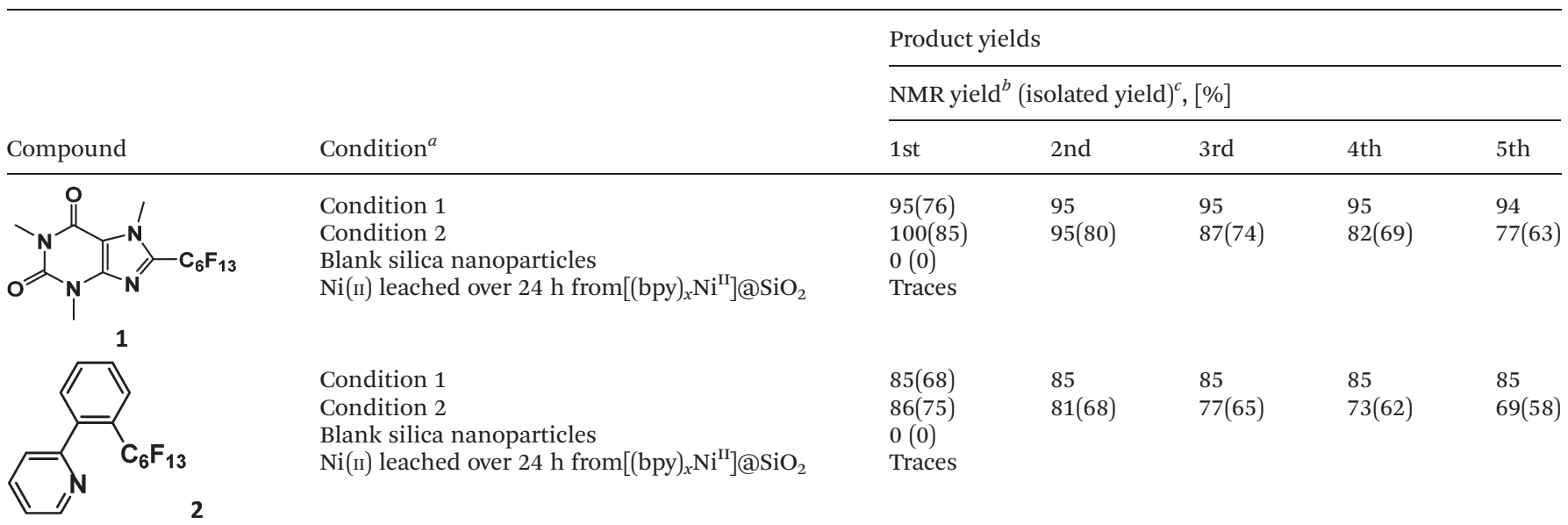

${ }^{a}$ Condition details are described in the ESI. ${ }^{b}$ NMR yields obtained by ${ }^{19} \mathrm{~F}$ NMR analysis of the crude reaction mixtures. ${ }^{c}$ Isolated yields with a $\mathrm{R}_{\mathrm{F}} \mathrm{COOH}$ base and $100 \%$ conversion using ${ }^{19} \mathrm{~F}$ NMR spectroscopy.

thetic mixture by phase separation. We examined catalytic activities of both blank silica particles and nickel ions and complexes in the supernatant solution after their leaching over 24 hours from [(bpy) $\left.)_{x} \mathrm{Ni}\right] @ \mathrm{SiO}_{2}$. The supernatant solution was obtained by separation through the centrifugation of $\left[(\mathrm{bpy})_{x} \mathrm{Ni}\right] @$ $\mathrm{SiO}_{2}$ from the solution. Experiments with blank (empty) silica particles under electrolysis oxidative conditions reveal the lack of target products of $\mathrm{C}-\mathrm{H}$ bond fluoroalkylation for both substrates (Table 2). Also, only a trace amount of a coupling product could be found in the reaction mixture after electrolysis of the electrolyte solution from which [(bpy $\left.)_{x} \mathrm{Ni}\right] @ \mathrm{SiO}_{2}$ has been removed by phase separation (Table 2 ).

Thus, for the first time, Ni(III) complex-catalyst particles were obtained by means of silica matrix stabilization, which are highly effective in oxidative functionalization reactions of $\mathrm{C}-\mathrm{H}$ bonds of aromatic compounds. The advantage of the developed catalyst is the high level of activity, the facile separation from the reaction mass, and the ability to be used multiple times. Moreover, applying conditions of the electrochemical regeneration in situ is the route to get high product yields under the low catalyst content, which is only $1 \%$ with respect to the substrates.

\section{Conclusions}

In conclusion, we have developed a new strategy for the $\mathrm{Ni}^{\mathrm{III}}$ NP-catalyzed direct fluoroalkylation of $\mathrm{C}-\mathrm{H}$ bonds of arenes (for example, 2-phenylpyridine or caffeine). A silica-supported $\left[(\mathrm{bpy})_{x} \mathrm{Ni}^{\mathrm{III}}\right] @ \mathrm{SiO}_{2}$ nanocatalyst was prepared electrochemically at room temperature without an additional oxidant. The coupling reaction of arenes and perfluoroheptanoic acid under nanoheterogeneous conditions occurs with $100 \%$ conversion of the reagents in a single step. The doping of metal complexes into silica nanoparticles produces an easily recyclable nano- heterogeneous catalyst, which in turn greatly broadens the catalytic applicability of transition metal complexes in the oxidative functionalization of aromatic $\mathrm{C}-\mathrm{H}$ bonds. This catalytic technique is both green and atom economical.

\section{Acknowledgements}

This work was supported by the Russian Science Foundation grant no. 14-23-00016.

\section{Notes and references}

1 S. Minakata and M. Komatsu, Chem. Rev., 2009, 109, 711.

2 V. Polshettiwar, C. Len and A. Fihri, Coord. Chem. Rev., 2009, 253, 2599.

3 A. P. Wight and M. E. Davis, Chem. Rev., 2002, 102, 3589.

4 J. C. Park, E. Heo, A. Kim, M. Kim, K. H. Park and H. Song, J. Phys. Chem. C, 2011, 115, 15772.

5 H. Tian, X. Li, L. Zeng and J. Gong, ACS Catal., 2015, 5, 4959.

6 J. C. Park, H. J. Lee, J. Y. Kim, K. H. Park and H. Song, J. Phys. Chem. C, 2010, 114, 6381.

7 C. Piovezan, J. M. R. Silva, A. Neves, A. J. Bortoluzzi, W. Haase, Z. Tomkowicz, E. E. Castellano, T. C. S. Hough and L. M. Rossi, Inorg. Chem., 2012, 51, 6104.

8 P. Lakshmanan, M. S. Kim and E. D. Park, Appl. Catal., A, 2016, 513, 98.

9 M. Kim, S. Lee, K. Kim, D. Shin, H. Kim and H. Song, Chem. Commun., 2014, 50, 14938.

10 S. Z. Tasker, E. A. Standley and T. F. Jamison, Nature, 2014, 509, 299.

11 N. M. Camasso and M. S. Sanford, Science, 2015, 347, 1218. 
12 M. I. Lipschutz and T. D. Tilley, Angew. Chem, Int. Ed., 2014, 126, 7418.

13 J. R. Bour, N. M. Camasso and M. S. Sanford, J. Am. Chem. Soc., 2015, 137, 8034.

14 A. Sivaramakrishna, H. S. Clayton and U. Muralikrishna, J. Coord. Chem., 2011, 64, 1309.

15 R. Mitra and K.-R. Pőrschke, Angew. Chem., Int. Ed., 2015, 54, 7488.

16 K. A. Jensen, Z. Anorg. Allg. Chem., 1936, 229, 275.

17 R. I. Haines and A. McAuley, Coord. Chem. Rev., 1981, 39, 77.

18 D. M. Grove, G. van Koten, W. P. Mul, A. A. H. Vanderzeijden, J. Terheijden, M. C. Zoutberg and C. H. Stam, Organometallics, 1986, 5, 322.

19 D. M. Grove, G. van Koten, R. Zoet, N. W. Murrall and A. J. Welch, J. Am. Chem. Soc., 1983, 105, 1379.

20 D. M. Grove, G. van Koten, P. Mul, R. Zoet, J. G. M. van der Linden, J. Legters, J. E. J. Schmitz, N. W. Murrall and A. Welch, J. Inorg. Chem., 1988, 27, 2466.

21 L. A. Van de Kuil, Y. S. J. Veldhuizen, D. M. Grove, J. W. Zwikker, L. W. Jenneskens, W. Drenth, W. J. J. Smeets, A. L. Spek and G. van Koten, J. Organomet. Chem., 1995, 488, 191.

22 C. M. Lee, C. H. Chen, F. X. Liao, C. H. Hu and G. H. Lee, J. Am. Chem. Soc., 2010, 132, 9256.

23 M. I. Lipschutz, X. Yang, R. Chatterjee and T. D. Tilley, J. Am. Chem. Soc., 2013, 135, 15298.

24 M. I. Lipschutz and T. D. Tilley, Angew. Chem., Int. Ed., 2014, 53, 7290.

25 V. M. Iluc and G. L. Hillhouse, J. Am. Chem. Soc., 2014, 136, 6479.

26 F. Tang, N. P. Rath and L. M. Mirica, Chem. Commun., 2015, 51, 3113.

27 Y. B. Dudkina, D. Y. Mikhaylov, T. V. Gryaznova, O. G. Sinyashin, D. A. Vicic and Y. H. Budnikova, Eur. J. Org. Chem., 2012, 2114.

28 Y. B. Dudkina, M. N. Khrizanforov, T. V. Gryaznova and Y. H. Budnikova, J. Organomet. Chem., 2014, 751, 301.

29 M. Khrizanforov, T. Gryaznova, O. Sinyashin and Y. Budnikova, J. Organomet. Chem., 2012, 718, 101.

30 D. Y. Mikhaylov, Y. H. Budnikova, T. V. Gryaznova, Y. Dudkina, M. Khrizanphorov, O. Kataeva and D. A. Vicic, Dalton Trans., 2012, 41, 165.

31 M. N. Khrizanforov, T. V. Gryaznova, D. Y. Mikhailov, Y. H. Budnikova and O. G. Sinyashin, Russ. Chem. Bull., 2012, 61, 1560.

32 D. Y. Mikhaylov, Y. H. Budnikova, T. V. Gryaznova, D. V. Krivolapov, I. A. Litvinov, D. A. Vicic and O. G. Sinyashin, J. Organomet. Chem., 2009, 694, 3840.

33 Yu. H. Budnikova, Yu. M. Kargin, J. Perichon and J.-Y. Nedelec, J. Organomet. Chem., 1999, 575, 63.

34 S. Yu, Y. Dudkina, H. Wang, K. V. Kholin, M. K. Kadirov, Y. H. Budnikova and D. A. Vicic, Dalton Trans., 2015, 44, 19443.

35 J. P. Kleiman and M. Dubeck, J. Am. Chem. Soc., 1963, 85, 1544.
36 Y. B. Dudkina, T. V. Gryaznova, Y. N. Osin, V. V. Salnikov, N. A. Davydov, S. V. Fedorenko, A. R. Mustafina, D. A. Vicic, O. G. Sinyashin and Y. H. Budnikova, Dalton Trans., 2015, 44, 8833.

37 J. Yoshida, R. Nakai and N. Kawabata, J. Org. Chem., 1980, 45, 5269.

38 H. Tanaka, Y. Kawakami, K. Goto and M. Kuroboshi, Tetrahedron Lett., 2001, 42, 445.

39 T. Liang, C. N. Neumann and T. Ritter, Angew. Chem., Int. Ed., 2013, 52, 8214.

40 M. G. Campbell, A. J. Hoover and T. Ritter, Top. Organomet. Chem., 2014, 52, 1.

41 O. A. Tomashenko and V. V. Grushin, Chem. Rev., 2011, 111, 4475.

42 M. Khrizanforov, S. Strekalova, V. Khrizanforova, V. Grinenko, K. Kholin, M. Kadirov, T. Burganov, A. Gubaidullin, T. Gryaznova, O. Sinyashin, L. Xu, D. A. Vicic and Y. Budnikova, Dalton Trans., 2015, 44, 19674.

43 S. V. Fedorenko, O. D. Bochkova, A. R. Mustafina, V. A. Burilov, M. K. Kadirov, C. V. Holin, I. R. Nizameev, V. V. Skripacheva and A. I. Konovalov, Phys. Chem. C, 2010, 114, 6350.

44 D. Zhang, Z. Wu, J. Xu, J. Liang, J. Li and W. Yang, Langmuir, 2010, 26, 6657.

45 J. Labéguerie-Egéa, H. M. McEvoy and C. McDonagh, J. Nanopart. Res., 2011, 13, 6455.

46 X. Wang, J. Zhou, W. Yun, S. Xiao, Z. Chang, P. He and Y. Fang, Anal. Chim. Acta, 2007, 598, 242.

47 H. Wei, L. Zhou, J. Li, J. Liu and E. Wang, J. Colloid Interface Sci., 2008, 321, 310.

48 W. Stöber, A. Fink and E. Bohn, J. Colloid Interface Sci., 1968, 26, 62.

49 A. R. Mustafina, S. V. Fedorenko, O. D. Konovalova, A. Yu. Menshikova, N. N. Shevchenko, S. E. Soloveva, A. I. Konovalov and I. S. Antipin, Langmuir, 2009, 25, 3146.

50 R. P. Bagwe, C. Yang, L. R. Hilliard and W. Tan, Langmuir, 2004, 20, 8336.

51 M. N. Khrizanforov, D. M. Arkhipova, R. P. Shekurov, T. P. Gerasimova, V. V. Ermolaev, D. R. Islamov, V. A. Miluykov, O. N. Kataeva, V. V. Khrizanforova, O. G. Sinyashin and Y. H. Budnikova, J. Solid State Electrochem., 2015, 19, 2883.

52 T. Gryaznova, Y. Dudkina, M. Khrizanforov, O. Sinyashin, O. Kataeva and Y. Budnikova, J. Solid State Electrochem., 2015, 19, 2665.

53 J. C. Brodovitch, R. I. Haines and A. McAuley, Can. J. Chem., 1981, 59, 1610.

54 U. Höchli, K. A. Müller and P. Wysling, Phys. Lett. A, 1965, 15,5 .

55 S. Bhattacharya, R. Mukherjee and C. Chakravorty, Inorg. Chem., 1986, 25, 3448.

56 A. Kassiba, M. Makowska-Janusik, J. Alauzun, W. Kafrouni, A. Mehdi, C. Reye, R. J. Corriu and A. Gibaud, J. Phys. Chem. Solids, 2006, 67, 875. 